\title{
Acute Cortisol Administration Promotes Sleep Intensity in Man
}

\author{
Elisabeth Friess*,', Hirokuni Tagaya', Claus Grethe', Lorenz Trachsel' and Florian Holsboer' \\ 'Max Planck Institute of Psychiatry, Munich, Germany
}

\begin{abstract}
The neuronal mechanisms of sleep generation, in particular synchronization of brain activity in the process of non-rapid-eye movement (non-REM) sleep, has been elucidated in the past decade. A previous study of our group showed that acute administration of cortisol is known to increase slow-wave sleep and suppress rapid-eye movement (REM) sleep in man. To further elucidate the non-REM sleeppromoting effects of cortisol with respect to the synchronization of cortical activity, it is important to establish a sleep-state-specific quantitative EEG analysis. We therefore investigated the effects of repetitive injections of hydrocortisone on spectral composition of sleep EEG in 10 healthy male young volunteers. In addition, we performed high-frequency blood samplings to assess the relation between changes in the sleep EEG and sleep-associated secretion of growth hormone $(\mathrm{GH})$. Cortisol administration resulted in a significant increase in highly synchronized EEG activity including delta and theta frequencies, according to a higher amount of slow-wave sleep. This effect predominated in the first few hours of night sleep. REM sleep was decreased, which appeared to be secondary to the lengthened first sleep cycle. The cortisol-induced stimulation of GH release did not occur in correspondence with the increased slow-wave activity. In view of the sleep impairing properties of corticotropin-releasing hormone $(\mathrm{CRH})$ and the sleep-promoting function of $\mathrm{GH}$-releasing hormone, it appears likely that a negative feedback inhibition of endogenous $\mathrm{CRH}$ was the key mechanism mediating the observed results. The cortisol-induced effects on sleep intensity and sleep-associated GH secretion appeared to be driven by different mechanisms. Neuropsychopharmacology (2004) 29, 598-604, advance online publication, 26 November 2003; doi: I 0.1038/sj.npp. I 300362
\end{abstract}

Keywords: hydrocortisone; growth hormone; sleep; slow wave; EEG power spectrum

\section{INTRODUCTION}

In humans, most studies on sleep EEG changes induced by acute cortisol administration observed a suppression of rapid-eye movement (REM) sleep and an increase in slowwave sleep as well as stimulation of sleep-associated release of growth hormone (GH) (Gillin et al, 1972; Born et al, 1989, 1991; Friess et al, 1994). The sleep-promoting effects of an acute cortisol administration were attributed to negative feedback inhibition of endogenous corticotropin-releasing hormone $(\mathrm{CRH})$, shifting the ratio of $\mathrm{CRH}$ and $\mathrm{GH}$-releasing hormone (GHRH) towards the latter. There is good evidence that the reciprocal interaction of the neuropeptides CRH and GHRH plays a key role in regulating sleep intensity, where GHRH acts as a sleep-promoting substance, at least in males, and CRH impairs sleep and increases wakefulness (for a review, see Steiger, 2002).

\footnotetext{
* Correspondence: E Friess, Max Planck Institute of Psychiatry, Kraepelinstr. 10, D-80804 Munich, Germany, Tel: +498930622 460, Fax: + 498930622 562, E-mail: friess@mpipsykl.mpg.de Received I4 April 2003; revised 15 October 2003; accepted 23 October 2003

Online publication: 27 October 2003 at http://www.acnp.org/citations/ Npp I0270303 | 6 / /default.pdf
}

However, the cortisol-induced effects on sleep appeared to be influenced by methodological aspects, that is, treatment administration (continuous $v s$ pulsatile, oral $v s$ intravenous), dosage, and chemical properties (synthetic vs natural) of the used compounds (for a review, see Friess et al, 1995). In our laboratories, the use of pulsatile drug administration has proved to be effective in detecting sleependocrine effects of endogenously released substances. A previous study of our group investigating the effects of repetitive hydrocortisone injections on sleep in healthy subjects showed that the steroid strongly increased slowwave sleep and suppressed REM sleep. However, this study was limited to conventional analysis of the sleep EEG (Friess et al, 1994).

This is a significant methodological limitation since neurophysiological findings on the generation of EEG synchronization during non-rapid-eye movement (nonREM) sleep emphasize the need for a quantitative analysis of certain EEG events. The transition from wakefulness to sleep is characterized by specific changes in macroscopic EEG, that is, the occurrence of sleep spindles defines loss of consciousness. Studies in cats showed that sleep spindles are generated by a distinct interplay between thalamic and thalamocortical neurons depending on their degree of membrane hyperpolarization (Steriade et al, 1994). In the 
course of further EEG synchronization, these neurons switch to slower oscillations in the delta frequency range, thus establishing slow-wave sleep in macroscopic EEG recordings. To further elucidate the sleep-promoting effect of acute cortisol, it appeared to be important to quantify the EEG spindle and delta frequencies in combination with the assessment of sleep-associated GH secretion.

Therefore, the present study investigated sleep-endocrine effects of hourly intravenous injections of hydrocortisone, including sleep-state-specific spectral analysis of the EEG and high-frequency blood sampling for measuring sleepassociated GH levels. The aim of the study was to clarify (1) whether acute administration of cortisol increases EEG synchronization during non-REM sleep (2) whether changes in the spectral composition of sleep EEG are related to sleep-associated GH secretion.

\section{METHODS}

\section{Subjects}

The study group consisted of 10 healthy male volunteers (mean age \pm SD: $25.5 \pm 2.7$ years, range: $22-30$ years). Before entering the protocol, the subjects underwent extensive physical, psychiatric, and laboratory examinations including hematology, virology, clinical chemistry, endocrinology, electroencephalography, and electrocardiography (ECG) to exclude acute and chronic disease. We excluded subjects who received any medical treatment for at least 3 months prior to the study, and had either personal or family history of psychiatric disorders, including alcohol and drug abuse, recent stressful life events, sleep disturbances, shift work, or a recent transmeridian flight.

\section{Procedure}

After written informed consent, the subjects participated in two experimental blocks that were separated by at least 1 week and consisted of two consecutive nights in our sleep laboratory. After adaptation to the laboratory setting (first night), the subjects received an indwelling forearm catheter at $1630 \mathrm{~h}$. According to a randomized schedule, either saline or hydrocortisone (HOECHST; Frankfurt, Germany) was intravenously administered hourly from 1700 to 0600 (total dose $1 \mathrm{mg} / \mathrm{kg}: 20 \%$ as initial loading dose, $6 \%$ every following hour). Blood specimens were collected every $20 \mathrm{~min}(1700-2300)$ and every $10 \mathrm{~min}$ from 2300 to 0700. The subjects remained in a semirecumbent position and were carefully observed by a TV camera to avoid sleep prior to 'lights off' at 2300. They received an electrolyte-balanced evening meal at 1900 , were allowed to watch TV, read, or listen to music. The experimental protocol was approved by the Ethics Committee for Human Experiments of the Max Planck Institute of Psychiatry.

\section{Hormone Measurement}

Plasma cortisol (ICN Biomedicals, Carson, CA) and GH (Nichols Institute, San Juan Capristano, CA) concentrations were measured by commercially available radioimmunoassay (RIA) kits. The detection limit for cortisol was $1.0 \mathrm{ng} / \mathrm{ml}$, and for GH $0.2 \mathrm{ng} / \mathrm{ml}$. The intra- and interassay coefficients of variation for cortisol and GH were below 7\%. All samples of one subject were measured in duplicate in one assay.

\section{Sleep EEG Recordings}

Polysomnographic sleep recordings (2300-0700) included two EEGs (C3-A2/C4-A1, high-pass filter at $0.53 \mathrm{~Hz}$, notch filter at $50 \mathrm{~Hz}$, low pass at $70 \mathrm{~Hz}$ ), a vertical and horizontal electrooculogram (EOG), electromyogram (EMG), and ECG. The filtered EOG, EEG, EMG, and ECG signals were transmitted to a polygraph (Schwartzer, ED 24), digitized via an eight-bit analog-to-digital converter (sampling rate $100 \mathrm{~Hz}$ ), and stored on disk. The spectral analysis was performed on C3-A2/C4-A1 EEG derivations using a fast Fourier transformation in order to compute sleep-statespecific EEG power spectra as described previously (Trachsel et al, 1994). State-specific power of 50 frequency bins at $0.39 \mathrm{~Hz}$ intervals were cumulated across the delta $(0.4-4.3 \mathrm{~Hz})$, theta $(4.3-7.8 \mathrm{~Hz})$, alpha $(7.8-12.1 \mathrm{~Hz})$, lower sigma $(12.1-14.1 \mathrm{~Hz})$, higher sigma $(14.1-16.2 \mathrm{~Hz})$, and beta $(16.2-19.1 \mathrm{~Hz})$ as described previously (Tagaya et al, 2000).

\section{Data Analyses}

Sleep stages were visually scored according to standard guidelines (Rechtschaffen and Kales, 1968) by experienced raters who were not aware of the treatment. The sleep parameters including sleep architecture and sleep continuity were computed as described elsewhere (Friess et al, 1994). For standardization, EEG spectral power data were expressed as their average power density during the corresponding time period of placebo night within the same frequency band and vigilance state. The hormone data were expressed as the area under the curve (AUC) using the trapezoid method. In addition, GH concentrations were submitted to a peak detection analysis as described by Veldhuis and Johnson (1986).

Treatment-induced differences in hormone data, sleep variables, and standardized spectral power data were identified by analysis of variance (ANOVA) with repeated measures design using treatment (cortisol $v s$ placebo) as the within-subject factor. Subsequent univariate F-tests were carried out in the case of significant treatment effects, and if time effects had to be considered as additional withinsubject factor, we used tests with contrast to identify significant differences between various time levels. As a nominal level of significance, $\alpha=0.05$ was accepted. To keep the type I error $\leqslant 0.05$ all posteriori tests were performed at a reduced level of significance (Bonferroniadjusted alpha). The Pearson product-moment correlation coefficient was used to test significant relations between some spectral power measures and hormone data.

\section{RESULTS}

\section{Cortisol and GH Levels}

The time-course changes in the plasma levels of cortisol and $\mathrm{GH}$ under the experimental conditions are shown in Figure 1.

The treatment resulted in a marked and continuous elevation of cortisol levels throughout the whole observation 
period and a significant increase in GH levels. Interestingly, the pattern of GH peaks was preserved, with significantly elevated $\mathrm{GH}$ levels in the hours before night sleep and slightly increased GH levels in the second half of the night. However, the major GH surge during the first few hours of non-REM sleep was not further increased by the treatment. The ANOVA for GH AUC-values $\left(\mathrm{ng} \times \mathrm{ml} \times \mathrm{min}^{-1} \times 10^{3}\right)$ in the total observation period (1700-0700), presleep period (1700-2300), first (2300-0300), and second half $(0300-0700)$ of the night revealed significant main effects (Wilks' multivariate test of significance) of treatment $\left(\mathrm{F}_{1,9}=6.12\right.$, sign. of $\mathrm{F}=0.035$, and time $\mathrm{F}_{2,8}=22.4$, sign. of $\mathrm{F}=0.001$ ), as well as a significant interaction effect of treatment and time $\left(\mathrm{F}_{2,8}=10.8\right.$, sign. of $\left.\mathrm{F}=0.005\right)$. Tests with contrasts pointed out that $\mathrm{GH}$ secretion was significantly enhanced in the presleep period (mean \pm SD: $0.36 \pm 0.59$ vs $1.06 \pm$ $\left.0.81 \mathrm{ng} \times \mathrm{ml} \times \min ^{-1} \times 10^{3} ; p<0.05\right)$ when compared with other time intervals. The ANOVA of the number of GH peaks (peak detection analysis of Veldhuis and Johnson, 1986) revealed a significant main effect (Wilks multivariate test of significance) of factors treatment $\left(\mathrm{F}_{3,16}=5.79\right.$, sign. of $\mathrm{F}=0.007)$ and time $\left(\mathrm{F}_{2,17}=14.06\right.$, sign. of $\left.\mathrm{F}=0.0002\right)$, and a significant treatment and time interaction effect $\left(\mathrm{F}_{2,17}=3.8\right.$, sign. of $\left.\mathrm{F}=0.04\right)$. The subsequent univariate F-test with $(1,18)$ DF identified a significant treatment effect
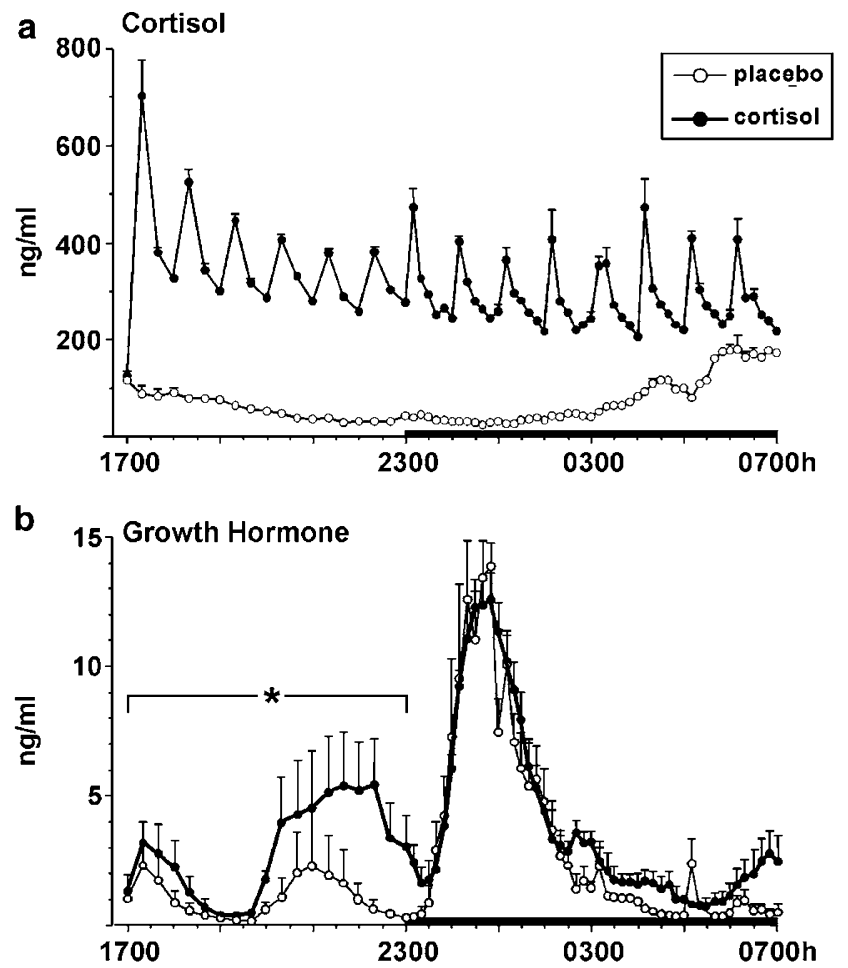

Figure I Time-course changes of sleep-associated cortisol and $\mathrm{GH}$. Time-course changes of the mean $( \pm$ SEM) plasma concentrations of $(a)$ cortisol and (b) $\mathrm{GH}(n=10)$. Closed circles depict the treatment condition and open circles depict the placebo condition. The cortisol injections resulted in a marked and continuous elevation of the cortisol concentrations and a significant increase in the growth hormone levels, in particular during the hours before night sleep. The peak detection analysis revealed a significant higher occurrence of presleep peaks in the treatment condition. * Sign. of F-values < 0.05 (ANOVA). on the number of GH peaks during the presleep period $(0.2 \pm 0.42$ vs $0.9 \pm 0.32 ; p<0.05)$.

\section{Sleep Architecture and Sleep Continuity}

The treatment had only minimal effects on variables reflecting sleep continuity. In contrast, sleep architecture was significantly altered by cortisol injections (see Table 1).

The ANOVA of sleep continuity parameters revealed no significant treatment effect $\left(\mathrm{F}_{6,4}=1.59\right.$, sign. of $\left.\mathrm{F}=\mathrm{NS}\right)$, whereas sleep architecture (sleep stage 1, sleep stage 2, slowwave sleep, REM sleep) was significantly affected by cortisol injections (Wilks' multivariate test of significance: $\mathrm{F}_{4,6}=6.77$, sign. of $\mathrm{F}=0.021$ ). Subsequent univariate F-tests with DF $(1,9)$ revealed significant treatment effects on slow-wave sleep and REM sleep (sign. of F-values $<0.05$ ). In addition, there was a significant treatment effect on latencies to sleep onset, slow-wave sleep and REM sleep, and the duration of the first, second, and third sleep cycle $\left(\mathrm{F}_{5,3}=9,89\right.$, sign. of $\left.\mathrm{F}=0.04\right)$. The subsequent univariate F-tests with DF $(1,7)$ identified the treatment effect on REM

Table I Sleep Continuity and Sleep Architecture

\begin{tabular}{|c|c|c|}
\hline & Placebo & Cortisol \\
\hline \multicolumn{3}{|l|}{ Sleep continuity } \\
\hline Time in bed & $470.5(14.0)$ & $478.5(2.3)$ \\
\hline Total sleep time & $439.8(14.1)$ & $425.4(38.2)$ \\
\hline Sleep period time & $456.4(11.9)$ & $451.1(19.6)$ \\
\hline Sleep efficacy index (\%) & $96.4(2.9)$ & $94.4(8.8)$ \\
\hline Wakefulness & $20.1(12.9)$ & $31.0(37.2)$ \\
\hline \multicolumn{3}{|l|}{ Sleep architecture } \\
\hline Sleep onset latency & | 3.6 (7.2) & | $8.4(8.6)$ \\
\hline REM sleep latency & $76.9(35.9)$ & | I $5.0(40.8)^{\mathrm{a}}$ \\
\hline Slow wave sleep latency & $32.3(36.5)$ & $32.3(30.3)$ \\
\hline Stage I sleep & $24.6(12.5)$ & $26.0(12.8)$ \\
\hline Stage 2 sleep & $267.2(32.1)$ & $270.4(46.6)$ \\
\hline Slow wave sleep & $49.6(35.1)$ & $64.0(39.5)^{\mathrm{a}}$ \\
\hline REM sleep & $91.0(21.4)$ & $54.2(16.9)^{\mathrm{a}}$ \\
\hline First sleep cycle & $95.1(37.0)$ & I30.0 (45.2) \\
\hline Non-REM sleep & $76.9(35.9)$ & I I $5.0(40.8)^{\mathrm{a}}$ \\
\hline REM sleep & $18.2(13.9)$ & |5.|( $(10.1)$ \\
\hline Second sleep cycle & $99.5(20.5)$ & $124.2(59.3)$ \\
\hline Non-REM sleep & $78.5(16.4)$ & I04.8(50.8) \\
\hline REM sleep & $21.1(11.4)$ & $19.4(11.9)$ \\
\hline Third sleep cycle $(n=8)$ & $108.7(45.7)$ & $106.7(19.2)$ \\
\hline Non-REM sleep & $87.3(42.3)$ & $88.6(15.4)$ \\
\hline REM sleep & $21.3(12.2)$ & |8.| (12.0) \\
\hline
\end{tabular}

Data represent mean $( \pm S D)$ in $\min (n=10)$ if not otherwise specified. We observed a significant treatment-induced increase in slow-wave sleep. The first sleep cycle was significantly lengthened due to an increase of non-REM sleep. The REM sleep latency was enhanced and the overall amount of REM sleep was suppressed by cortisol administration, although duration of REM sleep within the first three sleep cycles was similar between both experimental conditions. asign. of F-values $<0.05$.

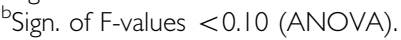


sleep latency (sign. of F-value $<0.05$ ) and the duration of the first sleep cycle (sign. of F-value <0.10). ANOVA of duration of non-REM sleep within sleep cycles revealed a significant treatment effect $\left(\mathrm{F}_{3,5}=7.26\right.$, sign. of $\left.\mathrm{F}=0.029\right)$ located in the first sleep cycle (univariate F-test with DF $(1,7)$ sign. of F-value $<0.05)$, whereas the amount of REM sleep within sleep cycles remained similar between both treatment conditions $\left(F_{3,5}=0.44\right.$, sign. of $\left.F=N S\right)$.

\section{Spectral Composition of the Sleep EEG}

The hourly cortisol injections induced a significant increase in EEG activity within delta and the theta range (Figure 2).

The ANOVA on standardized mean EEG activities, and the given frequency bands revealed a significant treatment effect (Wilks' multivariate test of significance) within the delta $\left(F_{1,9}=7.71\right.$, sign. of $\left.F=0.02\right)$ and theta band $\left(\mathrm{F}_{1,9}=5.56\right.$, sign. of $\left.\mathrm{F}=0.04\right)$, and the significant main effects of the factor time on delta $\left(\mathrm{F}_{2,8}=55.53\right.$, sign. of $\mathrm{F}=0.0001)$, theta $\left(\mathrm{F}_{2,8}=46.44\right.$, sign. of $\left.\mathrm{F}=0.0001\right)$, and alpha band $\left(\mathrm{F}_{2,8}=14.36\right.$, sign. of $\left.\mathrm{F}=0.002\right)$. In addition,
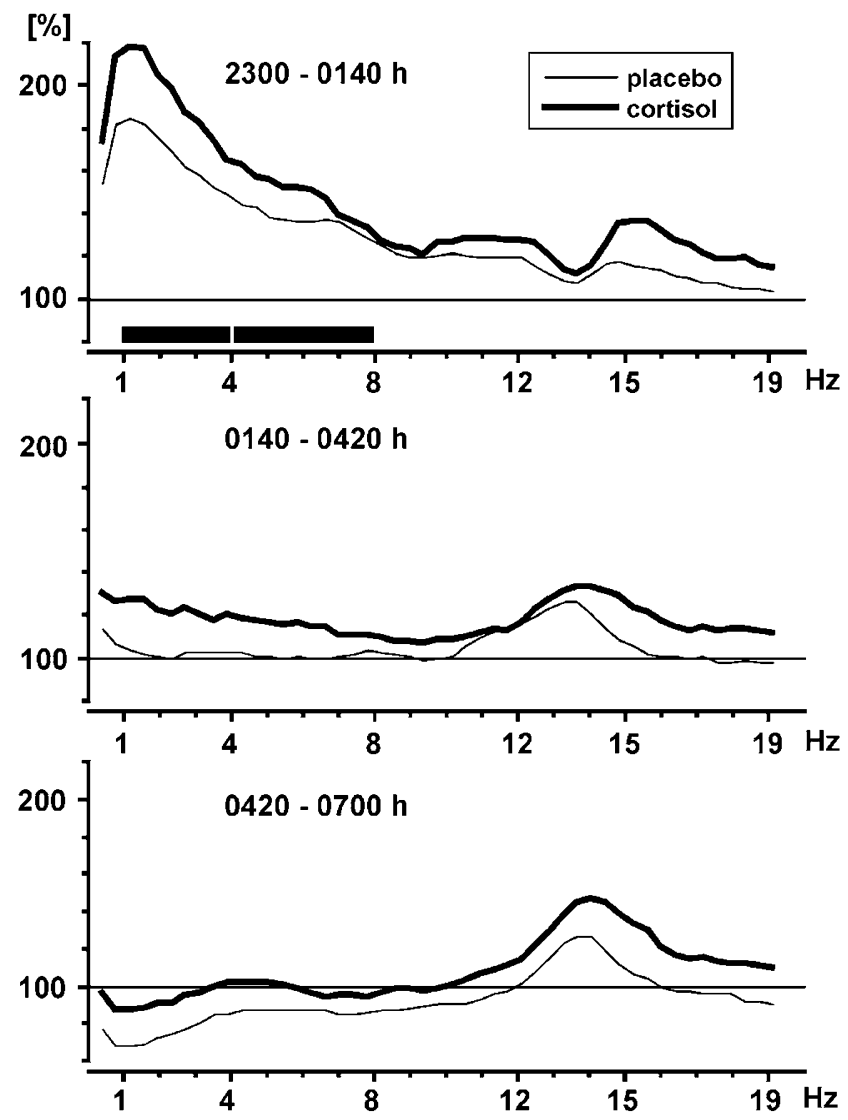

Figure 2 Spectral composition of non-REM sleep. EEG power spectra of non-REM sleep during three consecutive 160-min segments (thirds) of night sleep. For standardization, data were expressed as the percentage of their corresponding mean spectral power of the placebo night within the same frequency band and vigilance state $(=100 \%)$. Bold lines depict the mean values of the verum condition and thin lines depict the placebo condition $(n=10)$. The hourly cortisol injections induced a significant increase in the EEG activity within the delta and theta frequency range. Signs of F-values $<0.05$ (ANOVA) are shown as black bars above the abscissa. we observed an elevation of spectral power in higher sigma and beta frequencies that did not reach statistical significance.

\section{Temporal Dynamics of the Delta and Sigma EEG Activities}

In view of the well-established relation between delta and sigma EEG activity, we further investigated the dynamics of these frequencies within non-REM sleep episodes. However, we had to consider ultradian modulation due to treatmentinduced changes in sleep architecture, that is, increased length of the first sleep cycle. We therefore selected the first and last $30 \mathrm{~min}$ of non-REM sleep episodes that started or ended within three-thirds of the night as described previously (Tagaya et al, 2000). Figure 3 shows the temporal dynamics of slow-wave, lower and higher sigma EEG activities across non-REM sleep episodes.

Independent of the treatment condition, our data confirmed the well-known intra- and interepisodic relation of these frequencies: (1) in the first non-REM sleep episodes the surge of slow-wave activity was preceded and succeeded by the peaks of higher sigma EEG activity; (2) throughout the night slow-wave activity declined, whereas sigma EEG activities in particular within the lower sigma range increased. For statistical comparison, the first and last half hour of non-REM sleep episodes were subdivided into three consecutive 10-min segments. The ANOVAs were carried out on standardized 10-min mean EEG activity during nonREM sleep. Within the final part of the first non-REM sleep episodes, we observed a significant increase in delta frequencies. In the same time period, but in the beginning of the non-REM sleep episodes, we found a slight increase of higher sigma EEG activities that did not reach statistical significance. The spectral power in the lower sigma range seemed to be less affected by the treatment (see legend of Figure 3 for the results of the MANOVA).

Finally, we looked for an association between cortisolinduced changes in microstructure of sleep EEG, in particular, with respect to changes in delta power and nocturnal GH release, but failed to find any significant correlation between these variables.

\section{DISCUSSION}

This study examined sleep-endocrine effects of pulsatile cortisol injections in healthy male subjects by means of a sleep-state-specific quantitative analysis of the EEG, highfrequency blood sampling, and peak detection analysis of the GH secretion. We were able to confirm that the cortisol injections increased visually scored slow-wave sleep and stimulated nocturnal GH release as this has been described in both young (Friess et al, 1994) and elderly male subjects (Bohlhalter et al, 1997). Owing to the higher amount of nonREM sleep, there was a significant prolongation of the first sleep cycle and REM sleep latency. The overall time spent in REM sleep was markedly decreased, although the amount of REM sleep within sleep cycles remained fairly unchanged when compared to the placebo condition.

For further clarification of cortisol-induced effects on non-REM sleep, we established a quantitative EEG analysis 
a

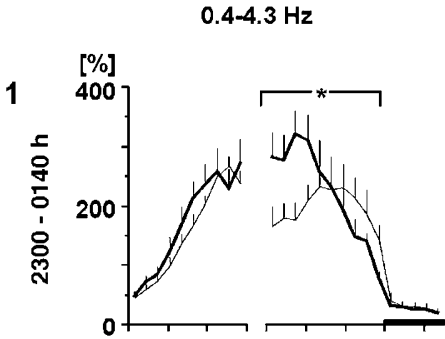

2

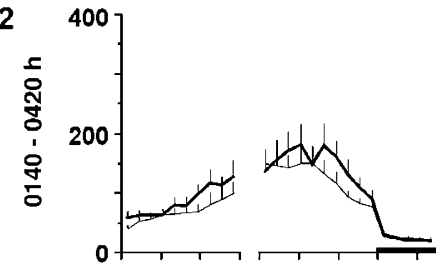

3

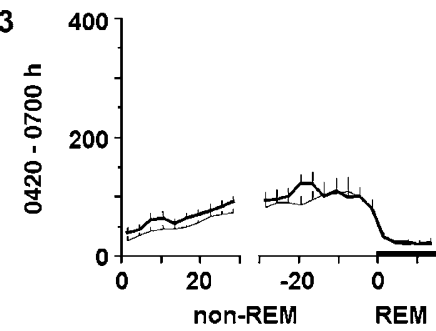

b Lower sigma activity 12.1- $14.1 \mathrm{~Hz}$
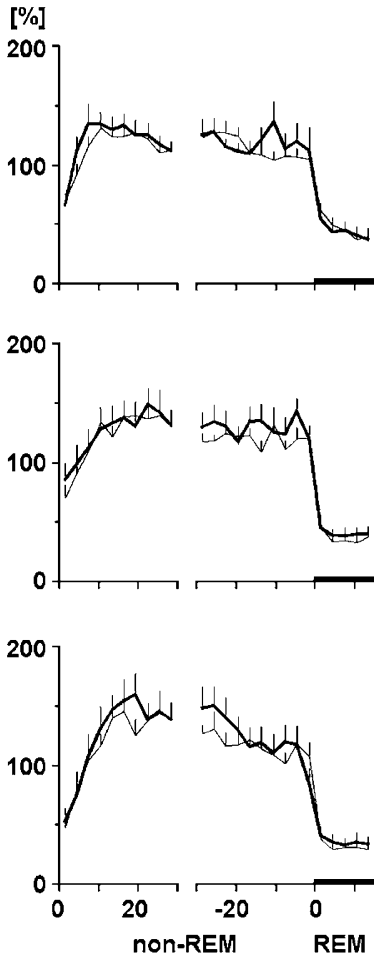

C Higher sigma activity $14.1-16.2 \mathrm{~Hz}$
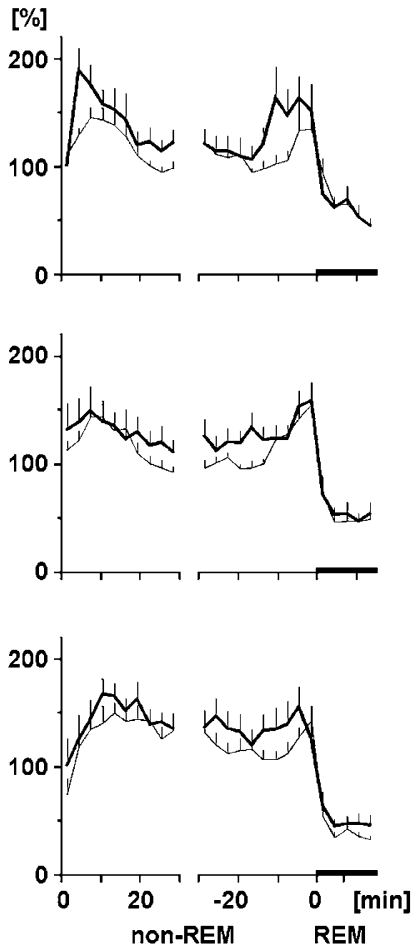

Figure 3 Temporal dynamics of delta and sigma EEG activities. Temporal evolution of the spectral power in the delta, lower, and higher sigma frequencies during the first and the last 30 min of the non-REM sleep episodes that began or ended within each of the three-thirds of night sleep; the thin line depicts placebo and the bold line depicts cortisol; data points represent the mean (+SE) EEG activity over 3 min of non-REM sleep; REM sleep is delimited by the dashed vertical lines. For statistical comparison, the first and the last half hour of non-REM sleep episodes were subdivided into three consecutive I0-min segments. The ANOVA carried out on the standardized I0-min mean EEG activity during non-REM sleep revealed: (I) 2300-0/40: (a) delta band: significant time effect in first $\left(F_{2,16}=40.06\right.$, sign. of $\left.F=0.000 \mathrm{I}\right)$ and last $30 \mathrm{~min}\left(\mathrm{~F}_{2,14}=6.68\right.$, sign. of $\left.\mathrm{F}=0.0 \mathrm{I} 2\right)$; significant interaction of effect of treatment and time in last $30 \mathrm{~min}\left(F_{2.14}=5.2\right.$, sign. of $\left.F=0.027\right)$; (b) lower sigma band: significant time effect in first $\left(F_{2,16}=6.16\right.$, sign. of $\left.F=0.02\right)$ and last 30 min $\left(F_{2,14}=4.73\right.$, sign. of $\left.F=0.05\right)$; (c) Higher sigma band: significant time effect in the first $\left(F_{2,16}=7.9 \mathrm{I}\right.$, sign. of $\left.F=0.007\right)$ and last 30 min $\left(F_{2,14}=5.94\right.$, sign. of $F=0.04$; marginal effect of treatment in the first $30 \mathrm{~min}\left(F_{1,8}=4.14\right.$, sign. of $\left.F=0.076\right)$; (2) 0140-0320: (a) delta band: significant time effect in first $\left(F_{2,18}=10.22\right.$, sign. of $\left.F=0.005\right)$, last $30 \mathrm{~min}: F_{2,14}=13.27$, sign. of $F=0.002 ;(b)$ lower sigma band: significant time effect in first 30 min: $F_{2,18}=11.46$, sign. of $F=0.005$; (c) higher sigma band, significant time effect in the first $\left(F_{2,18}=5.3\right.$, sign. of $\left.F=0.022\right)$ and last $30 \mathrm{~min}\left(F_{2,14}=13.33\right.$, sign. of $\left.F=0.006\right) ;(3) 0320$ 0700: (a) delta band: significant time effect in the first $30 \mathrm{~min}\left(F_{2.14}=18.12\right.$, sign. of $\left.F=0.0003\right)$; (b) lower sigma band: significant time effect in the first $\left(F_{2,14}=14.8\right.$, sign. of $\left.F=0.00 \mathrm{I}\right)$ and last $30 \mathrm{~min}\left(F_{2,16}=4.68\right.$, sign. of $\left.F=0.034\right)$; (c) Higher sigma band: significant time effect in the first 30 min $\left(F_{2,14}=5.78\right.$, sign. of $F=0.032$ ). * Sign. of $F$-values $<0.05$ (ANOVA; treatment by time interaction effect).

to obtain an EEG power spectrum and a temporal dynamics of delta and sigma frequencies within non-REM sleep episodes. The cortisol injections resulted in a significant increase in highly synchronized EEG activity within the delta and theta range $(0.4-7.8 \mathrm{~Hz})$ that corresponded to elevated visually scored slow-wave sleep. In addition, we observed a slight increase in higher sigma and beta frequencies $(14.1-19.1 \mathrm{~Hz})$. The analyses of the time course of delta and sigma EEG activities revealed that cortisolinduced increase in delta frequencies predominated at the end of the first non-REM sleep episodes. The elevation of higher sigma frequencies was pronounced in the beginning of the first non-REM sleep episode. The spectral power in the lower sigma range was less affected by the treatment.

Previous literature showed that temporal dynamics of sigma and delta frequencies in macroscopic EEG recordings reflect the process of EEG synchronization during non-REM sleep (for a review, see Steriade et al, 1994; Dijk, 1995). Electrophysiological data provided evidence that both generation of sleep spindles and EEG slow waves depend on the degree of membrane hyperpolarization of thalamocortical projecting neurons (Hirsch et al, 1983; Steriade et al, 1991; Steriade et al, 1993). Provided that there is a close link between thalamic events and cortical EEG, the process of EEG synchronization is reflected by an inverse occurrence of, in particular, high sigma and slow-wave frequencies throughout non-REM sleep episodes (Uchida et al, 1991; Lancel et al, 1992; Dijk et al, 1993; Aeschbach et al, 1994). Our results clearly demonstrated that this pattern was further pronounced by cortisol treatment. However, previous electrophysiological data and studies on the effect of sleep deprivation showed that conditions that increase delta EEG activity, that is, increased sleep pressure, typically decrease spindle frequencies (Brunner et al, 1990; Lancel et al, 1992; Dijk et al, 1993; Knoblauch et al, 2002). Electrophysiological data provided evidence that thalamocortical relay neurons can either oscillate in sigma or delta frequencies, but not at both frequencies at the same time (Nunez et al, 1992). Therefore, it seems unlikely that cortisol injections exerted a major influence on the 
intrathalamic generation of EEG frequency patterns, but modified the transmission of the signals into cortical target neurons or modified neuronal excitability at the cortical level. This is supported by an early study on the effects of cortisol on the brain activity during wakefulness (Feldman, 1971). The author reported immediately occurring convulsive effects of cortisol when directly administered to several subcortical brain regions of the cat.

Interestingly, the cortisol-induced slight increase in sigma activity was restricted to higher sigma frequencies. This confirms previous observations of a differential regulation of lower and higher sigma activity corresponding to the existence of two different types of sleep spindles (Jankel and Niedermayer, 1985; Scheuler et al, 1990; Friess et al, 1997; Tagaya et al, 2000; Zygierewicz et al, 1999). Yet it remains unclear as to why cortisol preferentially affected the higher frequency spindles. Is has to be mentioned, however, that our technique does not allow to discriminate between background activity and the occurrence of distinct EEG patterns like EEG spindles. In addition, due to the limitation to central derivations, we may have overestimated effects on the higher sigma spindles and underestimated effects on lower sigma spindles that predominate in the frontal brain regions (Jankel and Niedermayer, 1985; Scheuler et al, 1990; Werth et al, 1997; Zygierewicz et al, 1999).

With respect to the interaction of the hypothalamicsomatotrophic and hypothalamic-pituitary-adrenal (HPA) axis, the cortisol-induced sleep-endocrine effects may be explained by a dampening of the HPA system via negative feedback. The reduced activity of $\mathrm{CRH}$ would give way to an increased activity of GHRH since a sleep-associated reciprocal antagonism between these neuropeptides has been repeatedly demonstrated. Interestingly, the strong sleep-promoting effect of GHRH could only be demonstrated in young male and healthy subjects. The effects were weakened by conditions that change the ratio of $\mathrm{GHRH}: \mathrm{CRH}$ in favor of $\mathrm{CRH}$, that is, aging, depression, and also female sex (for a review, see Steiger, 2002). Since $\mathrm{CRH}$ and acute cortisol administration exert quite opposite sleep-endocrine effects, it appears likely that a negative feedback inhibition of endogenous CRH was the key mechanism mediating the observed results. This idea is supported by recent results showing that a treatment with CRH-1 receptor antagonist NB1-30775 was able to restore the slow-wave sleep deficit in patients with depression (Steiger et al, 2002). In addition, the replacement of corticosterone after adrenalectomy in rats, which is known to elevate $\mathrm{CRH}$, reversed the decrease in slow-wave sleep if the steroid was given in a physiological dose. In contrast, a supraphysiological corticosterone replacement reduced the amount of non-REM sleep (Bradbury et al, 1998). Although the cortisol injections in our study resulted in cortisol levels that were well above the sleep-associated peak values, we could not confirm the dose-dependent effects of corticosterone replacement observed in the adrenalectomized rats. Therefore, it would be of interest to study the effects of cortisol administration in a state of $\mathrm{CRH}$ hyperactivity in humans, that is, aging or depression.

As to the cortisol-induced endocrine effects, preclinical data provided evidence for a direct stimulation of $\mathrm{GH}$ by cortisol via the induction of gene expression (Treacy et al, 1991). We failed to find a significant association between slow-wave sleep and GH levels, which confirmed a previous report (van Cauter et al, 2000) but has been discussed controversially. Studies using more elaborate techniques to assess the $\mathrm{GH}$ secretion, that is, $30 \mathrm{~s}$ blood sampling or deconvolution procedure for statistical analyses, strongly support a close relationship between delta EEG activity and GH secretion (Holl et al, 1991; Gronifier et al, 1996). Although we established 10-min blood sampling and peak detection analysis, our results may still be confounded by methodological limitations. Interestingly, previous studies suggested that also the GHRH-induced increase in nonREM sleep is independent from the stimulation of GH (Obal and Krueger, 2001).

It has to be questioned whether cortisol promoted slowwave sleep at the cost of REM sleep or suppressed REM sleep and permitted an increased occurrence of slow-wave sleep. Since the duration of REM sleep within the first sleep cycles remained similar in both treatment conditions, our data suggest that the decrease in REM sleep was secondary to increased slow-wave sleep, in particular, within the first non-REM sleep episode. However, inhibitory effects of hydrocortisone on nicotinergic and muscarinergic ACh receptors have been described (Bouzat and Barrantes, 1993; Garbus et al, 2001; Yonekubo et al, 2002). Although studies on the interaction of cortisol with cholinergic generation of REM sleep at the brainstem level are lacking, it may be speculated that the observed effects on REM sleep were also directly mediated by the treatment.

In summary, acute pulsatile administration of cortisol promoted sleep intensity represented by an increased EEG synchronization, in particular, during the first non-REM sleep episode. The decrease in REM sleep appeared to be secondary to the stimulation of slow-wave sleep. We confirmed the stimulatory effects of cortisol on the release of GH that, however, were not correlated with those on sleep EEG.

\section{ACKNOWLEDGEMENTS}

We thank Norbert Tauchmann and Werner Laimgruber for their excellent technical assistance.

\section{REFERENCES}

Aeschbach D, Dijk DJ, Trachsel L, Brunner DP, Borbély AA (1994). Dynamics of slow-wave activity and spindle frequency activity in the human sleep EEG: effect of midazolam and zopiclone. Neuropsychopharmacology 11: 237-244.

Bohlhalter S, Murck H, Holsboer F, Steiger A (1997). Cortisol enhances non-REM sleep and growth hormone secretion in elderly subjects. Neurobiol Aging 18: 423-429.

Born J, DeKloet R, Wenz H, Kern W, Fehm HL (1991). Gluco- and mineralocorticoid effects on human sleep: a role of central corticoid receptors. Am J Physiol 260: E183-E188.

Born J, Späth-Schwalbe E, Schwakenhofer H, Kern W, Fehm HL (1989). Influences of corticotropin-releasing hormone (CRH), adrenocorticotropin (ACTH), and cortisol on sleep in normal man. J Clin Endocrinol Metab 68: 904-911.

Bouzat C, Barrantes FJ (1993). Hydrocortisone and 11-desoxycortisone modify acetylcholine receptor channel gating. Neuroreport 4: $143-146$.

Bradbury MJ, Dement WC, Edgar DM (1998). Effects of adrenalectomy and subsequent corticosterone replacement on 
rat sleep state and EEG power spectra. Am J Physiol 275: R555-R565.

Brunner DP, Dijk DJ, Tobler I, Bobély AA (1990). Effect of partial sleep deprivation on sleep stages and EEG power spectra: evidence for non-REM and REM sleep homeostasis. Electroencephalogr Clin Neuropyhsiol 75: 492-499.

Dijk DJ (1995). EEG slow waves and sleep spindles: windows on the sleeping brain. Behav Brain Res 69: 109-116.

Dijk DJ, Hayes B, Czeisler CA (1993). Dynamics of electroencephalographic sleep spindles and slow wave activity in men: effect of sleep deprivation. Brain Res 626: 190-199.

Feldman S (1971). Electrical activity of the brain following cerebral microinfusion of cortisol. Epilepsia 12: 249-262.

Friess E, Bardeleben UV, Wiedemann K, Lauer C, Holsboer F (1994). Effects of pulsatile cortisol infusion on sleep-EEG and nocturnal growth hormone release in healthy men. J Sleep Res 3: 73-79.

Friess E, Tagaya H, Trachsel L, Holsboer F, Rupprecht R (1997). Progesterone-induced changes in sleep in male subjects. Am J Physiol 272: E885-E891.

Friess E, Wiedemann K, Steiger A, Holsboer F (1995). The hypothalamic-pituitary-adrenocortical system and sleep in man. Adv Neuroimmunol 5: 111-125.

Garbus I, Bouzat C, Barrantes FJ (2001). Steroids differentially inhibit the nicotinic acetylcholine receptor. Neuroreport 12: 227-231.

Gillin JC, Jacobs LS, Fram DH, Snyder F (1972). Acute effect of a glucocorticoid on normal human sleep. Nature 237: 398-399.

Gronifier C, Luthringer R, Follenius M, Schaltenbrand N, Macher JP, Muzet A et al (1996). A quantitative evaluation of the relationships between growth hormone secretion and delta wave electroencephalographic activity during normal sleep and after enrichment in delta waves. Sleep 19: 817-824.

Hirsch JC, Fourment A, Marc ME (1983). Sleep-related variations of membrane potential in the lateral geniculate body relay neurons of the cat. Brain Res 259: 308-312.

Holl RW, Hartmann ML, Veldhuis JD, Taylor WM, Thorner MO (1991). Thirty-second sampling of plasma growth hormone in man: correlation with sleep stages. J Clin Endocrinol Metab 72: 854-861.

Jankel WR, Niedermayer E (1985). Sleep spindles. J Clin Neurophysiol 2: 1-35.

Knoblauch V, Krauchi K, Renz C, Wirz-Justice A, Cajochen C (2002). Homeostatic control of slow-wave and spindle frequency activity during human sleep: effect of differential sleep pressure and brain topography. Cereb Cortex 12: 1092-1100.

Lancel M, van Riezen H, Glatt A (1992). The time course of sigma activity and slow-wave activity during NREMS in cortical and thalamic EEG of the cat during baseline and after $12 \mathrm{~h}$ of wakefulness. Brain Res 596: 285-295.

Nunez A, Curro Dossi R, Contreras D, Steriade M (1992). Intracellular evidence for incompatibility between spindle and delta oscillations in thalamocortical neurons of cat. Neuroscience 48: 75-85.

Obal Jr F, Krueger JM (2001). The somatotropic axis and sleep. Rev Neurol 157: S12-S15.
Rechtschaffen A, Kales A (1968). A Manual of Standardized Terminology, Techniques and Scoring System for Sleep Stages of Human Subjects. Brain Information Service/Brain Research Institute UCLA: Los Angeles.

Scheuler W, Kubicki S, Scholz G, Marquardt J (1990). Two different activities in the sleep spindle frequency banddiscrimination based on the topographical distribution of spectral power and coherence. In: Horne J (ed). Sleep'90. Pontenagel Press: Bochum. pp 13-16.

Steiger A (2002). Sleep and the hypothalamo-pituitary-adrenocortical system. Sleep Med Rev 6: 125-138.

Steiger A, Held K, Künzel H, Ising M, Murck H, Holsboer F (2002). Corticotropin-releasing hormone receptor 1 antagonism counteracts sleep-EEG changes in depression. J Sleep Res 11(Suppl 1): 215-216.

Steriade M, Contreras D, Amzica F (1994). Synchronized sleep oscillations and their paroxysmal developments. Trends Neurosci 17: 199-208.

Steriade M, Dossi RC, Nunez A (1991). Network modulation of a slow intrinsic oscillation of cat thalamocortical neurons implicated in sleep delta waves: cortically induced synchronization and brainstem cholinergic suppression. J Neurosci 11: 3200-3217.

Steriade M, McCormick DA, Sejnowski TJ (1993). Thalamocortical oscillations in the sleeping and aroused brain. Science 262: 679-685.

Tagaya H, Trachsel L, Murck H, Antonijevic I, Steiger A, Holsboer F et al. (2000). Temporal dynamics of non-REM sleep episodes in humans. Brain Res 861: 233-240.

Trachsel L, Schreiber W, Holsboer F, Pollmacher T (1994). Endotoxin enhances EEG alpha and beta power in human sleep. Sleep 17: 132-139.

Treacy MN, Ryan F, Martin F (1991). Functional glucocorticoid inducible enhancer activity in the 5'-flanking sequences of the rat growth hormone gene. J Steroid Biochem Mol Biol 38: $1-15$.

Uchida S, Maloney T, March JD, Azari R, Feinberg L (1991). Sigma $(12-15 \mathrm{~Hz})$ and delta $(0.3-3 \mathrm{~Hz})$ EEG oscillate reciprocally within NREM sleep. Brain Res Bull 27: 93-96.

Van Cauter E, Leproult R, Plat L (2000). Age-related changes in slow wave sleep and REM sleep and relationship with growth hormone and cortisol levels in healthy men. JAMA 284: 861-868.

Veldhuis JD, Johnson ML (1986). Cluster analysis: a simple, versatile, and robust algorithm for endocrine pulse detection. Am J Physiol 250: E486-E493.

Werth E, Achermann P, Dijk DJ, Borbely AA (1997). Spindle frequency activity in the sleep EEG: individual differences and topographic distribution. Electroencephalogr Clin Neurophysiol 103: $535-542$.

Yonekubo K, Ohta T, Nakazato Y, Ito S (2002). Inhibitory effects of cortical steroids and adrenocorticotropic hormone on catecholamine secretion in guinea-pig perfused adrenal glands. Auton Autacoid Pharmacol 22: 93-101.

Zygierewicz J, Blinowska KJ, Durka PJ, Szelenberger W, Niemcewicz S, Androsiuk W (1999). High resolution study of sleep spindles. Clin Neurophysiol 110: 2136-2147. 